\title{
Work in Progress/Travaux en cours
}

\section{Shakespeare in the Theatre Research Group McGill University}

The Shakespeare in the Theatre Research Group is located in the Department of English of McGill University. The core group consists of John Ripley, Michael Bristol, Leanore Lieblein, Patrick Neilson, Denis Salter, and Catherine Shaw, with the active participation of a number of graduate students. It brings together scholars who, between them, have expertise in the area of theatre history, theatre practice, theatre aesthetics, and cultural theory and critique, to explore the history of Shakespeare in the theatre as an artistic, social, and political phenomenon, employing techniques developed by literary critics, historians, and cultural anthropologists. Its aim is to integrate lines of research which have traditionally been pursued in relative isolation.

Research sources for this work include promptbooks, account books, playbills, costume and set designs, lighting plots and othert heatre documents, illustrations, newspaper and periodical reviews, diaries, letters, and, for modern productions, discussions with theatre artists. The Research Group has begun to acquire promptbook collections on microfilm, which are available for use by other scholars and students.

Each year the Research Group selects a focus for its work, which is presented in monthly colloquia. The subject for 1993-94 was the nature of evidence for the stagecentred study of Shakespeare, and a volume on this subject, including invited contributions, is currently in preparation under the guest editorship of Edward Pechter of Concordia University. The focus for 1994-95 is in visual aspects of Shakespeare performance.

For further information on the Shakespeare in the Theatre Research Group, please write to Professor John Ripley, Department of English, McGill University, 853 Sherbrooke Street West, Montreal, Quebec H3A 2 T6. 